\title{
Synthesis and Improvement of Activity of Cobalt Organic Salts as Drier
}

\author{
Nader Zabarjad Shiraz, ${ }^{1}$ Bahram Letafat, ${ }^{1}$ Elaheh Sadat Sharifzadeh, ${ }^{2}$ and Anahita Rabii ${ }^{3}$ \\ ${ }^{1}$ Department of Chemistry, Islamic Azad University, Central Tehran Branch, Tehran 1467686831, Iran \\ ${ }^{2}$ Young Researchers Club, Islamic Azad University, Central Tehran Branch, B.O. Box 13185/768, Tehran, Iran \\ ${ }^{3}$ Department of Environmental Engineering, Graduate Faculty of Environment, University of Tehran, Tehran 1417853111, Iran
}

Correspondence should be addressed to Nader Zabarjad Shiraz; zabarjad_sh@yahoo.com

Received 28 November 2012; Accepted 17 December 2012

Academic Editors: M. Cieslak-Golonka and J. Moncol

Copyright (C) 2013 Nader Zabarjad Shiraz et al. This is an open access article distributed under the Creative Commons Attribution License, which permits unrestricted use, distribution, and reproduction in any medium, provided the original work is properly cited.

\begin{abstract}
Organic salts of cobalt were synthesized in the presence of amine, ethanol, and ethyl methyl ketoxime and were used as drier for alkyd resin. Considering the drying time of alkyd resin containing synthesized compound showed that amines, as electron releasing groups (ERG), increased the oxidizing activity of drier and shortened drying time about an hour, whereas ethyl methyl ketoxime delayed the drying of resin 2 hours. Two methods of synthesis, including solution and precipitation processes of synthesis, were compared in terms of convenience, cost, and environmental aspects.
\end{abstract}

\section{Introduction}

Metal alkanoates, metallic soaps, possessing interesting structural, and magnetic and photochemical properties have variety of applications in important areas such as material science, catalysis, and paint industries [1]. Among them, metal 2-ethyl hexanoates and their analogues are also used as fungicide, lubricating agents, plastic stabilizers, waterproof agents, and fuel additives [2]. As a catalyst, they are used in Ziegler nickel catalyst [3], stereoselective Diels-Alder reactions [4], and especially for oxidation and oligomerization of unsaturated chain of alkyd resin in paint industries [5].

Driers are a group of metallic soaps or salts containing either alkaline-earth metals or heavy metals. Common organic acids used are linolenic acid, rosin acids, tall fatty acid, naphthenic acid, and 2-ethyl hexanoic acid (2-EHA) [6]. Driers are added to air-drying coating systems to catalyze the oxidative cross-linking reactions [7]. Most of drier metals are in the oxidation state of +2 and usually dissolved in hydrocarbon solvents such as mineral spirit (clear liquid including a mixture of typically $>65 \% \mathrm{C} 10$ or higher of aliphatic and aromatic hydrocarbons) or aliphatic solvents.

Driers are often divided into two categories: primary and secondary driers. Primary (catalytic, surface, or oxidative) driers promote rapid surface drying [7]. Cobalt, manganese, vanadium, cerium, and iron-based catalysts belong to this group. Several physical and chemical experiments have been done to understand the nature of paint films during drying process [8]. Generally, evaporation of volatile materials, absorption of oxygen from the air, and formation of larger molecules from smaller ones take place to form dried film of paint [9]. Driers promote oxygen uptake, peroxide formation, and decomposition at ambient temperature. Free radicals produced in the process lead to the formation of polymerpolymer cross-links.

Drier accelerators such as 2,2-bipyridine (bpy) and 1,10-phenantroline are also extensively used. They function as chelating agents to form complexes with the primary driers. They apparently increase the activity of the metal towards decomposing peroxides [7]. Other chelating agents such as 2-aminomethylpyridine (amp) and 2hydroxymethylpyridine (hmp) were recently reported in combination with manganese-based catalysts [10].

Cobalt-based driers are often used in combination with other metals such as zirconium and calcium to obtain uniform drying. Bismuth soaps combined with cobalt driers were found to shorten the drying time of alkyd paints particularly under adverse conditions such as low temperature and high 
TABLE 1: Comparison of the effect of ligand on the activity of cobalt drier (3), $\lambda_{\max }$ and $\varepsilon$ of 6 .

\begin{tabular}{|c|c|c|c|c|}
\hline Drier & $\lambda_{\max }(\mathrm{nm})$ & $\varepsilon \mathrm{mol}^{-1} \mathrm{~cm}^{-1}$ & Drying (hr) & Explanation \\
\hline Blank & - & - & $>24$ & Cross-linking did not take place. \\
\hline 3 & 625 & 300 & 4 & As reference. \\
\hline $6 a$ & 690 & 370 & 3 & $\begin{array}{l}\text { Electron donating of nitrogen increased the } \\
\text { reactivity of cobalt. }\end{array}$ \\
\hline $6 b$ & 630 & 320 & 3 & $\begin{array}{l}\text { Resonance of electron pair of nitrogen with aromatic } \\
\text { ring made aniline ineffective. }\end{array}$ \\
\hline $6 c$ & 626 & 305 & 4 & $\begin{array}{l}\text { Positive charge of nitrogen resulted from the } \\
\text { coordination to cobalt made } \mathrm{Et}_{3} \mathrm{~N} \text { unreactive. }\end{array}$ \\
\hline 6d & 688 & 346 & 3 & $\begin{array}{l}\text { Electron donating of nitrogen increased the } \\
\text { reactivity of cobalt. }\end{array}$ \\
\hline $6 e$ & 635 & 332 & 5 & $\begin{array}{l}\text { Electronegativity of oxygen decreased the } \\
\text { nucleophilicity of the ligand. }\end{array}$ \\
\hline $6 f$ & 618 & 216 & 9 & $\begin{array}{l}\text { The stability of redox reaction products postponed } \\
\text { the cross linking. }\end{array}$ \\
\hline
\end{tabular}

humidity [11]. It has also been reported that combination of aluminium compounds with cobalt driers leads to a significant increase in the hardness of the alkyd paint films [12].

Risk analysis studies showed that inhalation exposure to cobalt in humans has been reported to result in cough, dyspnea, decreased pulmonary function, weight loss, diffuse nodular fibrosis, and respiratory hypersensitivity. Contact with cobalt in humans has resulted in dermatitis, with eruptions of the erythematous papular type on the ankles, elbows, and neck [13]. Chronic exposure to cobalt by inhalation in humans results in effects on the respiratory system, such as respiratory irritation, wheezing, asthma, pneumonia, and fibrosis. Other effects include cardiac effects, such as functional effects on the ventricles and enlargement of the heart; congestion of the liver, kidneys, and conjunctiva; and immunological effects that include cobalt sensitization, which can precipitate an asthmatic attack in sensitized individuals [14].

However the increase in environmental regulations makes the knowledge of cobalt drier chemistry of the utmost importance. Replacement of the toxic cobalt salts as driers in alkyd paint still poses a challenge [15]. Although exclusion of cobalt drier is an ultimate favourite method to eliminate its environmental risks in resin and paint industries, reduction of its consumption may be an alternate to diminish resulting hazards. In this paper we try to use some electron donating ligands to improve the drying activity of cobalt octoate, and consequently decrease dosage of cobalt drier in alkyd resins and paints.

\section{Experimental}

Long oil alkyd (60\% in mineral spirit) was used as blank resin. Aniline, ethanolamine, ethyl amine, ethyl methyl ketoxime, cobalt sulfate, and cobalt hydroxide were purchased from fluka and were used without further purification.
2.1. General Procedure for Synthesis of Cobalt Octoate (3) (Solution Method). A mixture of $\mathrm{Co}(\mathrm{OH})_{2}$ (1) (93 g, $1 \mathrm{~mol}$ ) and 2-EHA (2) (288 g, $2 \mathrm{~mol}$ ) in mineral spirit (1 L) was stirred magnetically and heated up to $150-160^{\circ} \mathrm{C}$ to separate the produced $\mathrm{H}_{2} \mathrm{O}(33.1 \mathrm{~mL}, 92 \%)$ by Dean-Stark apparatus. After departure of the $\mathrm{H}_{2} \mathrm{O}$ as by-product, the mixture was heated for an hour and the drier obtained as a deep violet solution. The metal content of drier was adjusted to $10 \%$ by adding adequate mineral spirit.

2.2. General Procedure for Synthesis of Cobalt Drier (3) (Precipitation Method). To a magnetically stirred solution of $\mathrm{CoSO}_{4}$ (4) (15.5 g, $\left.0.1 \mathrm{~mol}\right)$ in $\mathrm{H}_{2} \mathrm{O}(50 \mathrm{~mL})$ was added dropwise a solution of organic acid (2) (0.2 mol) in $\mathrm{NaOH}$ solution $(10 \%, 50 \mathrm{~mL})$. After 2 hours refluxing, the precipitate (3) was filtered, washed with water, and dried at room temperature (32.8 g, 95\%). The solid was dissolved in mineral spirit to prepare $10 \%$ cobalt drier solution.

2.3. Technique to Evaluate Drier Activity. Conventional methods used to determine drying time of oil or paint film often involved a drying time recorder [16]. Other methods for determining the activity of driers are included; for example, the measurement of viscosity change and sample weight increase over time [17] or more modern techniques such as ${ }^{13}$ C NMR [18], GC [9], HPLC [19], FTIR [20], and MS [21] have been used to study the effects of drier on the paint film. However, in this project finger touch method was employed for drying time study [22].

To have a blank sample, $1 \mathrm{~kg}$ of alkyd resin (60\%) was mixed with calcium drier ( $5 \mathrm{~g}, 5 \%$ metal) and lead drier ( $5 \mathrm{~g}$, $32 \%$ metal). Synthesized cobalt drier (3 or 6) ( $0.5 \mathrm{gr}$ ) was added to $100 \mathrm{~g}$ of prepared blank and stirred thoroughly to get homogeneous liquid. Then a layer of resin (100 micron) was applied on the glass and the touch drying time of resin was measured according to ISO 9117-6 procedure. The results of touch drying time were summarized in Table 1. 


$$
\mathrm{CoSO}_{4}+2 \mathrm{C}_{7} \mathrm{H}_{15} \mathrm{CO}_{2} \mathrm{H} \underset{\mathbf{1}}{\stackrel{\mathrm{NaOH}}{\longrightarrow}} \underset{2}{\mathrm{Co}\left(\mathrm{O}_{2} \mathrm{C}-\mathrm{C}_{7} \mathrm{H}_{15}\right)_{2}+\mathrm{Na}_{2} \mathrm{SO}_{4}}
$$

Scheme 1: Synthesis of cobalt octoate in $\mathrm{NaOH}$ solution.

$\mathrm{Co}(\mathrm{OH})_{2}+2 \mathrm{C}_{7} \mathrm{H}_{15} \mathrm{CO}_{2} \mathrm{H} \longrightarrow \mathrm{Co}\left(\mathrm{O}_{2} \mathrm{C}-\mathrm{C}_{7} \mathrm{H}_{15}\right)_{2}+2 \mathrm{H}_{2} \mathrm{O}$

42

3

Scheme 2: Synthesis of cobalt octoate in mineral spirit.

\section{Results and Discussions}

There are several methods for synthesis of metal alkanoates including metathesis reactions [23-25], ligand exchange reactions [7], and anodic dissolution of metal in alkanoic acid. In this project the reaction of $\mathrm{CoSO}_{4}$ (1) with 2-EHA (2) in the presence of $\mathrm{NaOH}$ solution led to synthesis of cobalt octoate (3) (Scheme 1).

In an alternative method, cobalt octoate (3) was synthesized via the reaction of $\mathrm{Co}(\mathrm{OH})_{2}$ (4) and 2-EHA (2) in mineral spirit as solvent (Scheme 2).

Comparison of drier production methods showed that solvent process was time consuming. In solution method, water was removed continuously using Dean-Stark, which could be used as an easy procedure for monitoring of the reaction progress. In solvent process, the product was homogeneous. Because of the lack of interfering by-product, there was no problem in production of insoluble salt.

In spite of difficulties of precipitation method such as filtration and elution, it benefited from some advantages. Solid content of drier was $100 \%$, which not only made the transportation easier and safer, but also provided the ability to produce driers with high metal content.

To investigate effects of organic ligands on the reactivity of cobalt drier, some ligands $(\mathrm{L}-\mathrm{H}, 5)$ were added to cobalt octoate (3) solution and refluxed at $150-160^{\circ} \mathrm{C}$ for $2 \mathrm{hrs}$ (Scheme 3).

Resulted modified driers (6) were added to alkyd resin, the drying time was measured according to finger touch method and results and some explanations were summarized in Table 1.

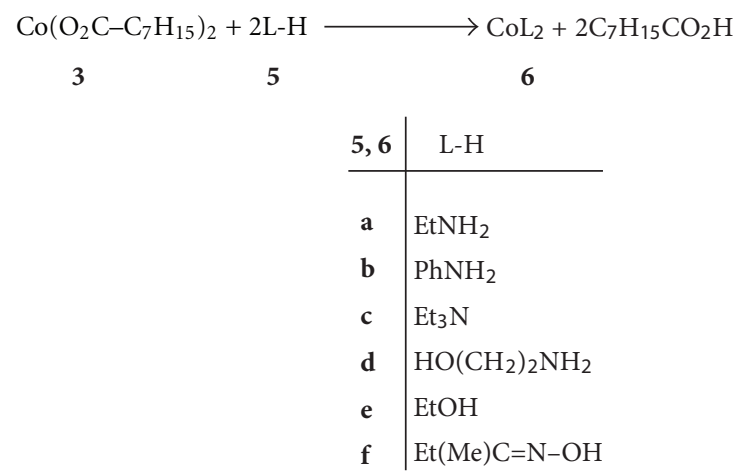

Scheme 3: Modification of cobalt octoate (3) by ligands (5). (a)
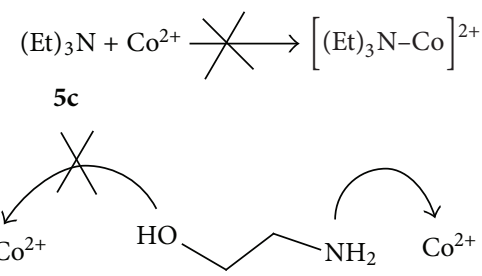

$5 d$

(c)

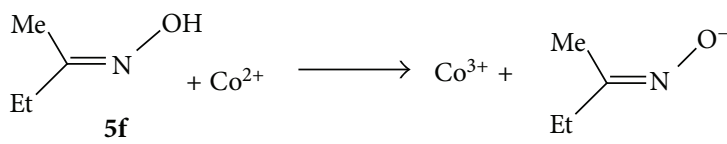

Scheme 4: Effect of ligands on activity of $\mathrm{Co}^{2+}$.

Comparison of behaviour and activity of ligands showed that amines, good electron donors, helped Co (II) to increase the rate of oxidation in unsaturated chains of alkyd resin. Aliphatic amine (5a) was more efficient than aromatic ones. Amine $3^{\circ}$ was not suitable for this purpose because positive charge on nitrogen appeared as a result of attack of amine to cobalt (Scheme 4(a)).

Alcohols and amino alcohol were not efficient for this purpose either, because oxygen is more electronegative than nitrogen, so it does not have much nucleophilicity (Scheme 4(b)).

It seemed that Co (II) formed an unstable complex with oxime [26] and had not adequate tendency to react with polymer and delayed drying time (Scheme 4(c)).

Although various spectroscopic methods such as X-ray, crystallography, ${ }^{1} \mathrm{H},{ }^{13} \mathrm{C}$ NMR, EPR, and UV-Vis spectra have been employed for identification and characterization of metal alkanoates, in this study, added ligands (5) changed the color of drier. So, UV-Vis spectrum was used to measure $\lambda_{\max }$ of drier (Table 1) [27]. Cobalt octoate had $\lambda_{\max }=625 \mathrm{~nm}$ and appropriate absorption $\left(\varepsilon=300 \mathrm{~mol}^{-1} \mathrm{~cm}^{-1}\right)$ in the visible region due to ${ }^{4} \mathrm{~T}_{1} \mathrm{~g}(\mathrm{~F})$ to ${ }^{4} \mathrm{~T}_{2} \mathrm{~g}^{(\mathrm{F})}$ transitions. The deep color of cobalt drier made it unsuitable for white paints. The visible spectrum of driers possessing oxime showed that the $\lambda_{\max }$ had shifted to shorter wave length $(618 \mathrm{~nm})$ and molar absorption coefficient had reduced $\left(\varepsilon=210 \mathrm{~mol}^{-1} \mathrm{~cm}^{-1}\right)$ in the visible region. The visible spectra patterns of the driers except aniline were the same as the blank drier and showed that unpaired electrons of nitrogen participated in resonance with the ring instead of coordinating to cobalt. Visible spectrum of the drier including ethyl amine or ethanol amine showed that coordination of amine to Co (II) made $\lambda_{\max }$ shifted to 690 and $688 \mathrm{~nm}$, respectively, and caused an increase in the oxidizing ability of Co (II).

\section{Conclusions}

Comparison of drier production methods showed that selection of method depends on the raw materials, transportation, desire metal content of drier, and tendency to have a facility for production monitoring. Thanks to good electron releasing 
power of amines, they were the best choice for increasing the efficiency of driers.

Although modification of cobalt drier reduced the amount of cobalt consumption and consequently could help environmental protection, many efforts are essential to use environmentally friendly driers instead of cobalt drier.

\section{References}

[1] W. Lu, Y. Ding, Y. Chen, Z. L. Wang, and J. Fang, "Bismuth telluride hexagonal nanoplatelets and their two-step epitaxial growth," Journal of the American Chemical Society, vol. 127, no. 28, pp. 10112-10116, 2005.

[2] D. Diaz, M. Rivera, T. Ni et al., "Conformation of ethylhexanoate stabilizer on the surface of CdS nanoparticles," Journal of Physical Chemistry B, vol. 45, p. 9854, 1999.

[3] S. Sabata and J. Hetflejs, "Syntheses of triblockpolybutadienepolydimethylsiloxane copolymers by coupling reactions," Journal of Applied Polymer Science, vol. 85, p. 1185, 2002.

[4] D. B. Gorman and I. A. Tomlinson, "Iron(III) 2-ethylhexanoate as a novel, stereoselective hetero-Diels-Alder catalyst," Chemical Communications, no. 1, pp. 25-26, 1998.

[5] F. Micciche, J. V. Haveren, E. Oostveen, and W. Ming, "Metal 2-ethylhexanoates and related compounds as useful precursors in materials science," Applied Catalysis A, vol. 297, pp. 174-181, 2006.

[6] S. M. P. Meneghetti, R. F. Souza, A. L. Monteiro, and M. O. Souza, "Transformation of triglycerides into fulels, polymers and chemicals: some applications of catalysis in oleochemistry," Progress in Organic Coatings, vol. 33, pp. 219-224, 1998.

[7] J. H. IngoldBieleman, Additives for Coatings, Wiley-VCH, Weinheim, Germany, 2000.

[8] R. A. Sailer and M. D. Soucek, "Investigation of cobalt drier retardation," European Polymer Journal, vol. 36, no. 4, pp. 803-811, 2000

[9] W. J. Muizebelt, J. C. Hubert, and R. A. M. Venderbosch, "Mechanistic study of drying of alkyd resins using ethyl linoleate as a model substance," Progress in Organic Coatings, vol. 24, no. 1-4, pp. 263-279, 1994.

[10] J.-Z. Wu, E. Bouwman, and J. Reedijk, "Chelating ligands as powerful additives to manganese driers for solvent-borne and water-borne alkyd paints," Progress in Organic Coatings, vol. 49, pp. 103-108, 2004.

[11] R. G. Middlemiss and D. J. Olszanski, "New catalysts for highsolids coatings-part 1," American Paint \& Coatings Journal, vol. 78, pp. 35-43, 1993.

[12] W. J. Muizebelt, J. C. Hubert, R. A. M. Venderbosch, A. J. H. Lansbergen, R. P. Klaasen, and K. H. Zabel, "Aluminum compounds as additional crosslinkers for air-drying high-solids alkyd paints," Journal of Coatings Technology, vol. 70, no. 882, pp. 53-59, 1998.

[13] NLM (National Library of Medicine). Hazardous Substances Databank, 1999.

[14] ATSDR (Agency for Toxic Substances and Disease Registry), “Toxicological Profile for Cobalt. TP-91/10," Public Health Service, U.S. Department of Health and Human Services, Atlanta, Ga, USA, 1992.

[15] European Council of producers and importers of paints, http://www.cepe.org.
[16] N. Indictor, C. J. Shahani, N. S. Baer, and M. J. D. Low, "Alkyd paint and paint driers," Journal of Coatings Technology, vol. 50, p. 54, 1978.

[17] W. J. Muizebelt, J. J. Donkerbroek, M. W. F. Nielen et al., "Methods for studying the drying of alkyd paint using ethyl linoleate as a model compound," Journal of Coatings Technology, vol. 70, pp. 83-92, 1998.

[18] J. C. Hubert, R. A. M. Venderbosch, W. J. Muizebelt, R. P. Klaasen, and K. H. Zabel, "Mechanistic study of drying of alkyd resins using (Z,Z)- and (E,E)-3,6-nonadiene as model substances," Progress in Organic Coatings, vol. 31, no. 4, pp. 331-340, 1997.

[19] J. Mallegol, J. L. Gardette, and J. Lemaire, "[Mn(acac)3] as a drying catalyst for alkyd paints," Journal of the American Oil Chemists' Society, vol. 76, pp. 967-976, 1999.

[20] W. J. Muizebelt and M. W. F. Nielen, "Fast autoxidation of ethyl linoleatecatalyzed by $[\mathrm{Mn}(\mathrm{acac}) 3]$ and bipyridine: a possible drying catalyst for alkyd paints," Journal of Mass Spectrometry, vol. 31, pp. 545-554, 1996.

[21] ISO 9117-3, "Paints and varnishes-drying tests-part 3: surface-drying test using ballotini," 2010.

[22] B. Kozlevčar, N. Lah, S. Makuc, P. Šegedin, and F. Pohleven, "Copper(II) carboxylates-synthesis, structure and biological activity. IV. Fatty acid copper(II) carboxylates with urea," Acta Chimica Slovenica, vol. 47, no. 4, pp. 421-433, 2000.

[23] M. Rusjan, Z. Chaia, O. E. Piro, D. Guillon, and F. D. Cukiernik, "Synthesis, structure and magnetic properties of tetrakis$\mu$-carboxylato-bis(dodecylnicotinato)dicopper(II) complexes; crystal and molecular structure of the decyl carboxylate derivative," Acta Crystallographica Section B, vol. 56, no. 4, pp. 666-672, 2000.

[24] N. Lah, G. Giester, J. Lah, P. Šegedin, and I. Leban, "2-Amino-3(hydroxymethyl)pyridinium 2-benzoylbenzoate monohydrate," New Journal of Chemistry, vol. 25, pp. 753-759, 2001.

[25] G. B. Deacon and R. Phillips, "Synthesis and structural characterisation of the zinc carboxylate bis(Ferrocenedicarboxylato) bis(1-methylimidazole-dizinc(II). A structure displaying a bimetallic macrocyclic framework," Coordination Chemistry Reviews, vol. 33, p. 227, 1980.

[26] S. Tanase, J. C. Hierso, E. Bouwman et al., "New insights on the anti-skinning effect of methyl ethyl ketoxime in alkyd paints," New Journal of Chemistry, vol. 27, no. 5, pp. 854-859, 2003.

[27] H. Ashour Dawood, R. Khalaf, and Z. Salman, "Cobalt(II), Nickel(II), and Copper(II) complexes with ligands contain nitrogen as donor atoms type $\mathrm{N} 3$ and azamacrocylic N6, synthesis and characterisation," Iraqi National Journal OfChemistry, vol. 35, p. 489, 2009. 

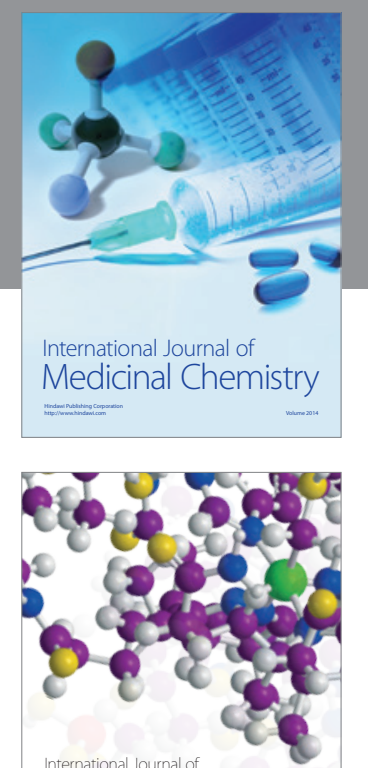

\section{Carbohydrate} Chemistry

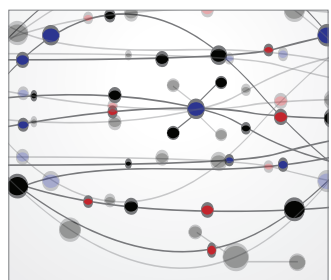

The Scientific World Journal
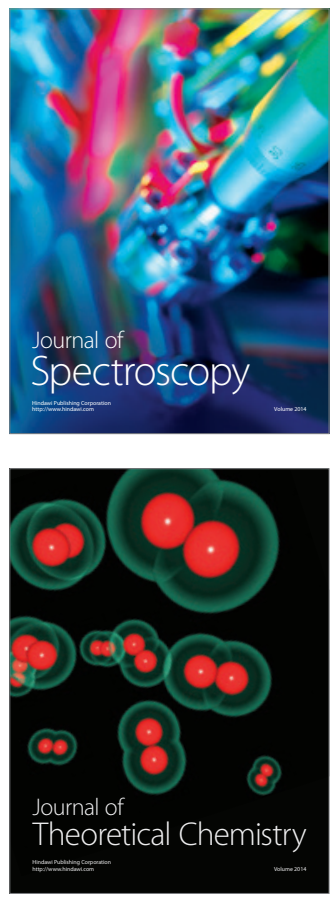
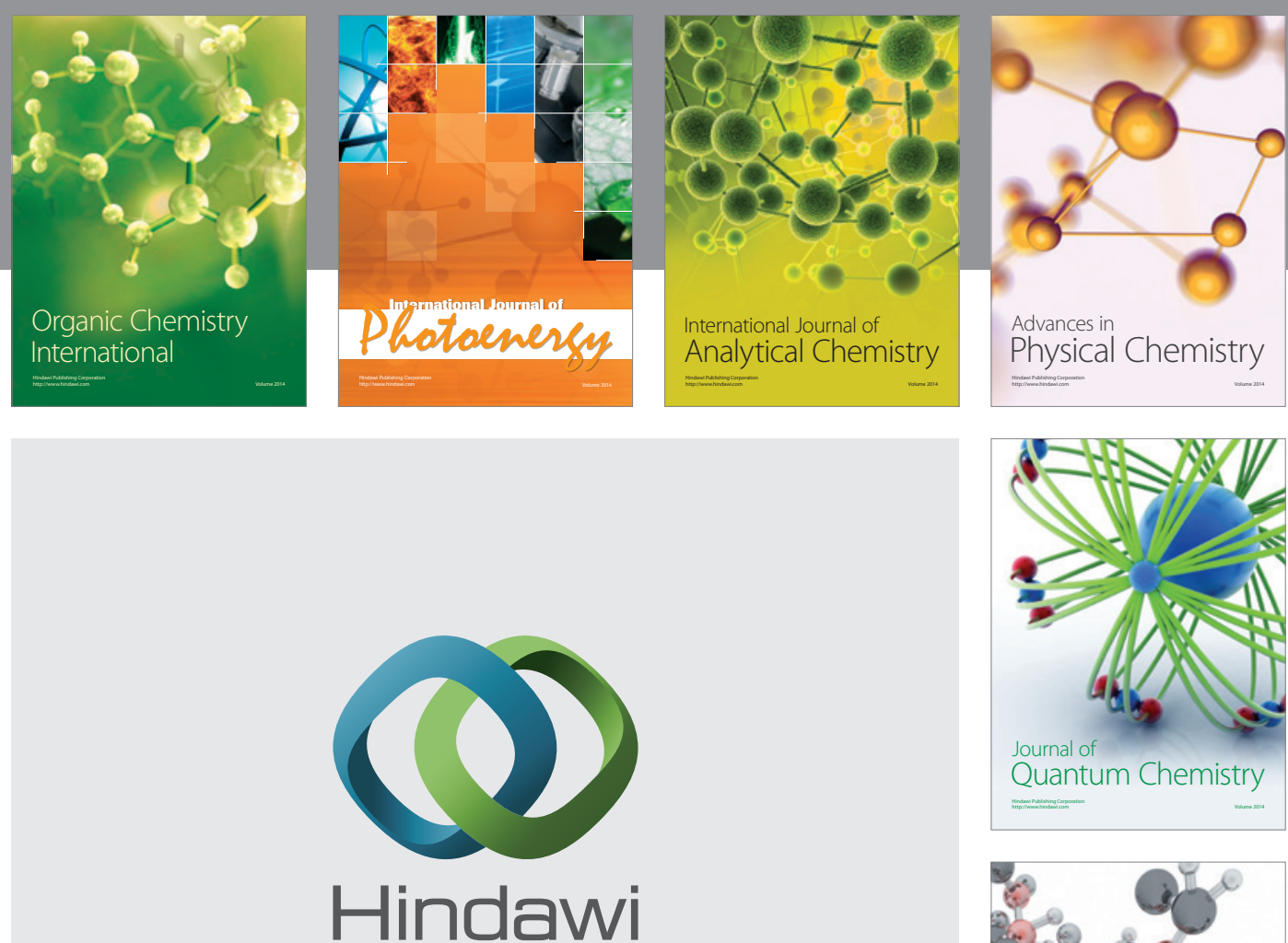

Submit your manuscripts at

http://www.hindawi.com

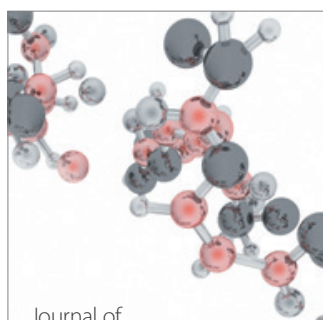

Analytical Methods

in Chemistry

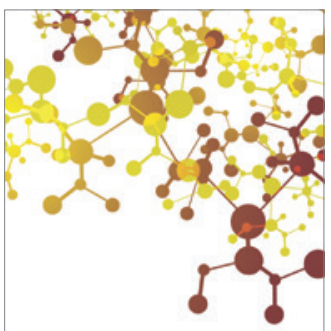

Journal of

Applied Chemistry

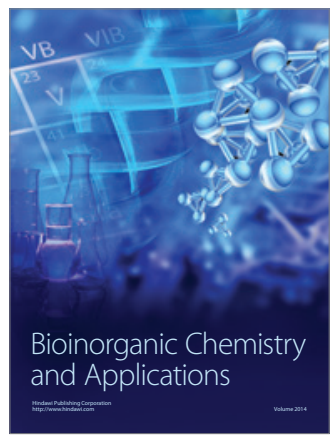

Inorganic Chemistry
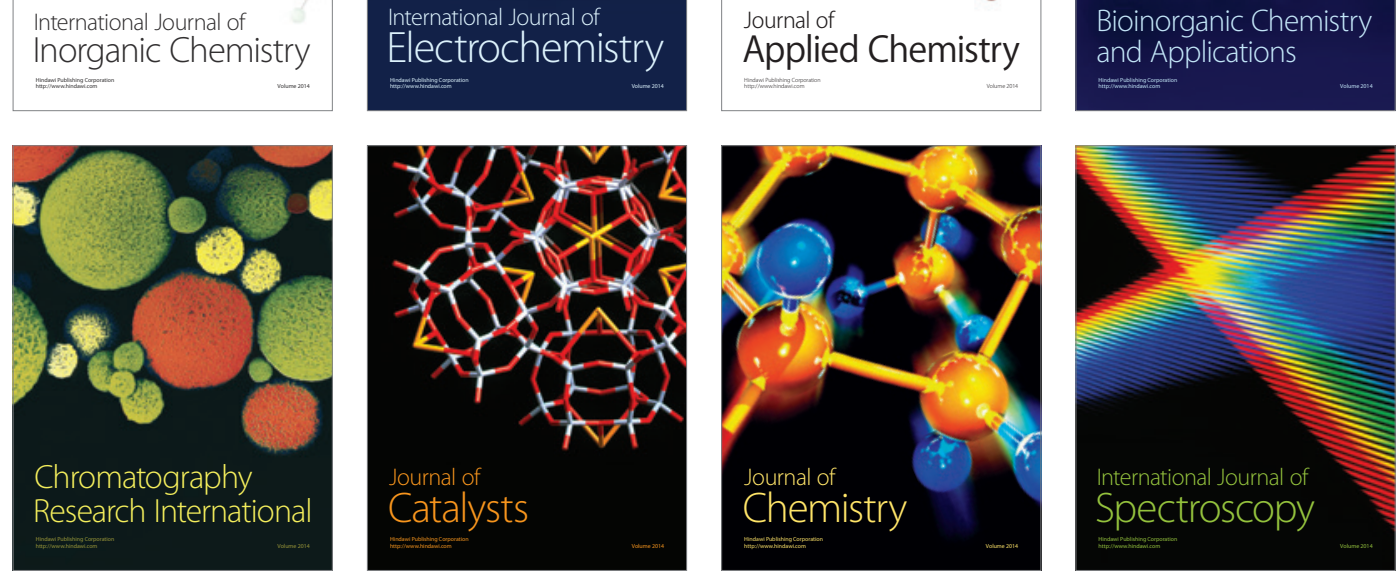